\title{
Influence of Fiber Orientation on Structural Performance of Beam-Column Joints using PVA FRCC
}

\author{
Yu $\mathrm{Mu}^{1}$, Mai Ando ${ }^{2}$, Akira Yasojima ${ }^{3}$ and Toshiyuki Kanakubo ${ }^{4}$ \\ ${ }^{1}$ Department of Engineering Mechanics and Energy, University of Tsukuba, 1-1-1 \\ Tennodai, Tsukuba, 305-8573, Japan; PH+81(29)853-5462; FAX+81(29)853-5207; email: \\ s1530211@u.tsukuba.ac.jp \\ ${ }^{2}$ Department of Engineering Mechanics and Energy, University of Tsukuba, 1-1-1 \\ Tennodai, Tsukuba, 305-8573, Japan; PH+81(29)853-5462; FAX+81(29)853-5207 \\ ${ }^{3}$ Department of Engineering Mechanics and Energy, University of Tsukuba, 1-1-1 \\ Tennodai, Tsukuba, 305-8573, Japan; PH+81(29)853-5257; FAX+81(29)853-5207; email: \\ yasojima@kz.tsukuba.ac.jp \\ ${ }^{4}$ Department of Engineering Mechanics and Energy, University of Tsukuba, 1-1-1 \\ Tennodai, Tsukuba, 305-8573, Japan; PH+81(29)853-5045; FAX+81(29)853-5207; email: \\ kanakubo@kz.tsukuba.ac.jp
}

\begin{abstract}
In recent years, many studies on fiber-reinforced cementitious composite (FRCC) has been conducted actively to improve brittle behavior of cementitious materials. FRCC shows the improved tensile performance and ductility because fibers across the crack can transfer tensile force after first cracking. When fibers tent to orient perpendicularly to crack surface, higher bridging effect of fibers is observed. When fibers tend to orient parallel to crack, however, bridging performance of fibers becomes poor. As one of the examples, the authors have already conducted that the casting direction of FRCC influences the tensile performance of FRCC. The objective of this study is to investigate the influence of fiber orientation on structural performance of PVA FRCC beam-column joint by using two types of casting method. Horizontal and vertical casting beam-column joint specimens are tested by reversed cyclic load simulating earthquake force. A vibrator rod is also applied during the casting. The applied load on beams and the story drift angle of two specimens are obtained directly from the experiment. According to the experimental results, specimens of horizontal casting and vertical casting show almost the same shear capacities. Using a vibrator rod during casting has an influence on shear capacity of PVA FRCC beam-column joint.
\end{abstract}

Keywords: horizontal casting; vertical casting; vibrator; fiber orientation; shear capacity; 


\section{INTRODUCTION}

Fiber-reinforced cementitious composite is cement composite with the mixture of short fibers to increase strength and ductility of cement composite. Comparing to the conventional concrete, FRCC has a remarkable deformability especially under tensile and bending load with large energy absorption capacity due to the effect of fiber bridging. After first cracking, fiber can transfer tensile force through crack which strongly affects the tensile performance of FRCC. When fibers tent to orient perpendicularly to crack surface, higher effect of bridging of fibers is observed. When fibers tend to orient parallel to crack, however, bridging performance of fibers becomes poor.

FRCC is a typical self-compacting cementitious matrix with a high viscosity. It has been considered that fresh-state properties, casting method, vibration, flow and framework, etc. have the effect on the orientation of fibers (Laranjeira et. al., 2012). For tensile characteristics of FRCC, the authors have already studied the influence of casting direction on the fiber orientation of FRCC through a visualization simulation and higher tensile stress of the second peak was observed in horizontal casting specimens than that of vertical casting specimens (Kanakubo et al., 2016).

The authors (Sano et al., 2015, Yamada et al., 2016) have also reported the study on structural performance of beam-column joints using FRCC in panel zone with a fiber volume fraction of $1 \%$. It has been confirmed that fibers can restrain expansion of crack width, increase shear capacity and improve structural performance rather than the specimen without fiber. These results may indicate that casting direction may affect the structural performance of PVA FRCC beam-column joint due the difference of fiber orientation.

Precast construction method which is used in reinforced concrete buildings especially in high skyscraper becomes more and more popular by ensuring better quality, simplified install procedure and shorter duration. Until now, a new precast system which casting the joint panel combining with beam and separating column into two parts has been proposed. By adopting this precast method, different kinds of casting direction can be attempted due to the independence of joint panel. Therefore, it is a smart way of enable FRCC to play a better role in a beam-column joint.

In this study, loading test of two PVA FRCC beam-column joints with a fiber volume fraction of $1 \%$ are conducted to evaluate the effect of casting direction on structural performance and crack behavior of panel joint by which horizontal casting and vertical casting are applied before manufacture. The mix proportion of used PVA FRCC is the same one in the previous study (Kanakubo et al., 2016) except for the fiber volume fraction. In that study, it was obtained that the maximum tensile stress after first cracking of horizontal casting specimens shows 2.1 times higher than that of vertical casting specimens.

In this study, furthermore, a vibrator rod is used to reorient the fiber. The authors have reported that using a compacting vibrator shows an effectiveness to improve the bending behavior of FRCC (Watanabe et al., 2016). Fig.1 shows the example of visualization simulation using water glass solution conducted as like previous study (Kanakubo et al., 2016). The black-colored "target fibers" made from nylon were added to the matrix to ease 
the observation of fiber orientation. The cross-sectional size of the mold is $180 \mathrm{~mm} x$ $280 \mathrm{~mm}$. The right-side photo shows the upper surface of the matrix after vibration using a compacting vibrator. It can be clearly observed that the fibers orient along concentric circles centering the point of vibrating. In this study, a vibrator rod is inserted into the matrix along with the direction of casting to arrange the fiber orientation of panel zone. The influence of using a vibrator rod during casting is also discussed based on the experimental results.
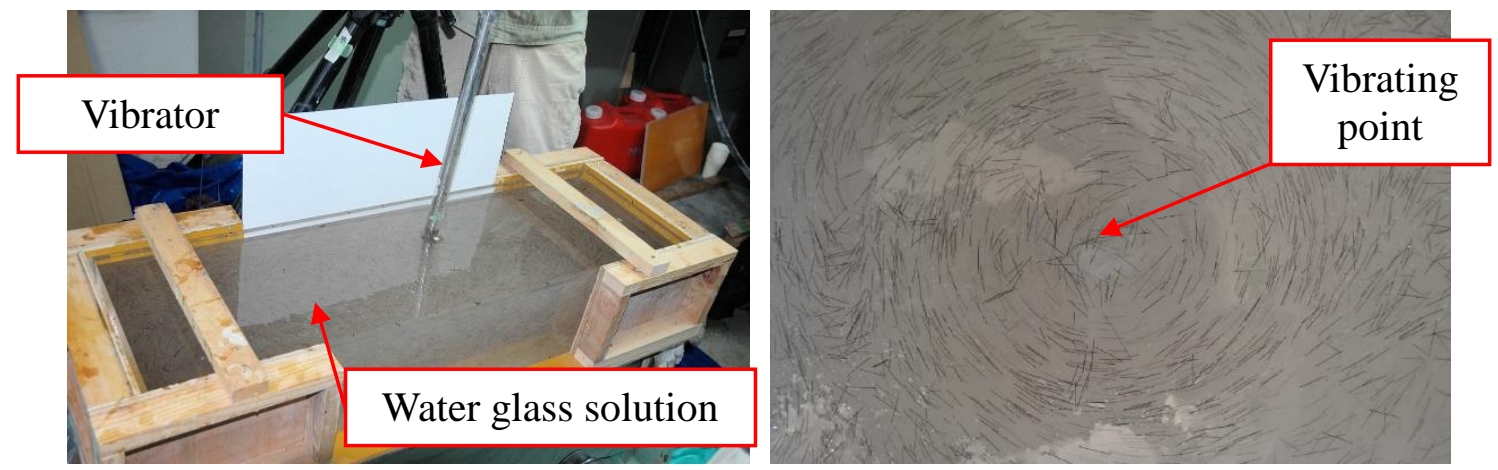

Figure 1. Example of fiber orientation after vibrating

\section{EXPERIMENTAL PROGRAM}

\section{Test specimens}

The dimension of specimens is show in Fig. 2. PVA fiber is used for all specimens with a fiber volume fraction of 1\%. Two types of casting method, as shown in Fig. 3, which is horizontal casting and vertical casting were used. During the casting, a vibrator rod was being inserted into the matrix along with the direction of casting to arrange the fiber orientation of panel zone. The testing parameter is the casting direction along the horizontal and vertical directions. Specimens are listed in Table. 1. Specimen No. 24 and No. 25 of which have been reported in the previous study (Sano et al., 2015) are also discussed. Specimen No.24 is the control sample in which there is no fiber in panel zone. Horizontal casting is applied on specimen No.25 in which 1\% of PVA fiber is used. Characteristics of PVA fiber are listed in Table 2. The beam section and column section are set to $380 \mathrm{~mm} \times 420 \mathrm{~mm}$ and $500 \mathrm{~mm} \times 500 \mathrm{~mm}$ separately by considering the scale of real internal beam-column joint in skyscraper buildings. All specimens are designed to fail by shear in panel zone before flexural yielding to evaluate the shear performance of joint panel. High strength reinforcing bars are adopted to ensure the safety margin of joint shear capacity to be approximately 0.6 . Mechanical properties of concrete and PVA FRCC are listed in Table 3. 


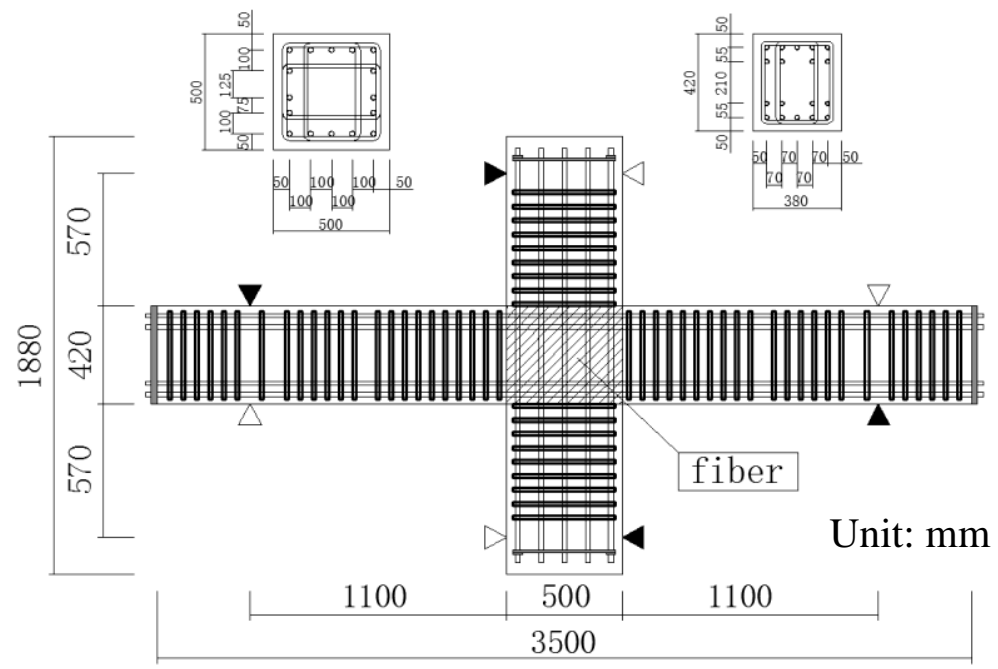

Figure 2. Specimen dimensions

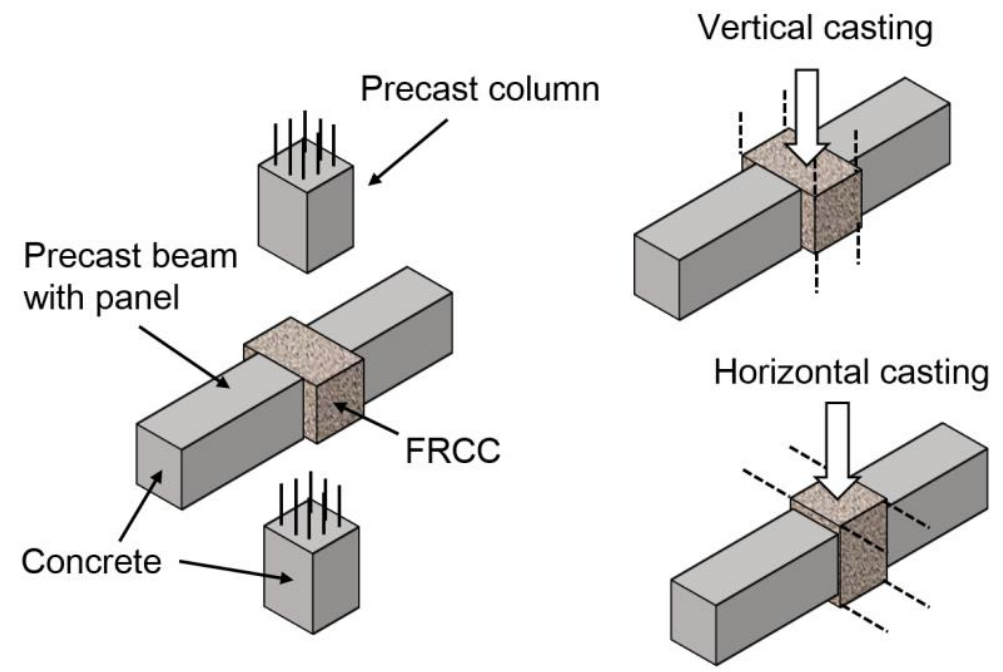

Figure 3. Casting directions

Table 1. Specimens list

\begin{tabular}{c|c|c|c|c|c}
\hline \multirow{2}{*}{ ID } & Panel & \multicolumn{2}{|c|}{ Beam } & \multicolumn{2}{c}{ Column } \\
\cline { 2 - 3 } & Parameter & $\begin{array}{c}\text { Reinforcing } \\
\text { bar }\end{array}$ & Stirrup & $\begin{array}{c}\text { Reinforcing } \\
\text { bar }\end{array}$ & Hoop \\
\hline No.24* & Without fiber & & & & \\
\cline { 1 - 2 } No.25* & Horizontal casting & 18-D22 & 6-D10@60 \\
No.32 & $\begin{array}{c}\text { Horizontal casting } \\
\text { Vibrator }\end{array}$ & (USD685) & $\begin{array}{c}\text { 16-D22 } \\
\text { (USD685) }\end{array}$ & $\begin{array}{c}\text { 6-D10@60 } \\
\text { (SD785) }\end{array}$ \\
\hline No.33 & $\begin{array}{c}\text { Vertical casting } \\
\text { Vibrator }\end{array}$ & & & \\
\hline
\end{tabular}


Table 2. Mechanical properties of fiber

\begin{tabular}{c|c|c|c|c}
\hline Fiber & $\begin{array}{c}\text { Length } \\
(\mathrm{mm})\end{array}$ & $\begin{array}{c}\text { Diameter } \\
(\mathrm{mm})\end{array}$ & $\begin{array}{c}\text { Tensile strength } \\
(\mathrm{MPa})\end{array}$ & $\begin{array}{c}\text { Elastic modulus } \\
(\mathrm{GPa})\end{array}$ \\
\hline PVA & 12.0 & 0.10 & 1200 & 28 \\
\hline
\end{tabular}

Table 3. Mechanical properties of concrete and PVA FRCC

\begin{tabular}{|c|c|c|c|c|c|}
\hline Type & ID & Place & $\begin{array}{c}\text { Compressive } \\
\text { strength }(\mathrm{MPa})\end{array}$ & $\begin{array}{l}\text { Splitting tensile } \\
\text { strength (MPa) }\end{array}$ & $\begin{array}{c}\text { Elastic } \\
\text { modulus }(\mathrm{GPa})\end{array}$ \\
\hline \multirow{2}{*}{ Concrete } & No. $24^{*}$ & \multirow{2}{*}{$\begin{array}{c}\text { Beam } \\
\text { Column }\end{array}$} & 39.9 & 3.55 & 29.6 \\
\hline & No. $25^{*}$ & & 39.1 & 3.42 & 28.0 \\
\hline \multirow{2}{*}{$\begin{array}{c}\text { PVA } \\
\text { FRCC }\end{array}$} & No. $24^{*}$ & \multirow{2}{*}{$\begin{array}{l}\text { Panel } \\
\text { zone }\end{array}$} & 50.3 & - & 17.6 \\
\hline & No. $25^{*}$ & & 52.5 & - & 17.6 \\
\hline \multirow{2}{*}{ Concrete } & No.32 & \multirow{2}{*}{$\begin{array}{c}\text { Beam } \\
\text { Column }\end{array}$} & 75.5 & 4.47 & 35.0 \\
\hline & No.33 & & 75.6 & 4.11 & 33.3 \\
\hline \multirow{2}{*}{$\begin{array}{c}\text { PVA } \\
\text { FRCC }\end{array}$} & No.32 & \multirow{2}{*}{$\begin{array}{l}\text { Panel } \\
\text { zone }\end{array}$} & 49.1 & - & 17.1 \\
\hline & No.33 & & 48.0 & - & 15.7 \\
\hline
\end{tabular}

"Specimens No.24 and No.25 are from the previous study (Sano et al., 2015)

\section{Loading method and measurement}

The reversed cyclic loading is applied to the beams by controlling story drift angles from $\mathrm{R}= \pm 1 / 400$ to $\pm 1 / 20 \mathrm{rad}$. The story drift angle was controlled by actuators attached to the inflection points of the beams. Oil jacks were used on the inflection points to support the columns.

\section{EXPERIMENTAL RESULT}

\section{Load-story drift angle curve and failure mode}

The relationship between the applied load on beams (average of both beams) and the story drift angle of specimen No.32 and No.33 are shown in Fig. 4. The maximum load of specimen No.32 was observed at the cycle of 1/50 rad and that of No.33 was at 1/67 rad. After the maximum load, although the crack width increased with the increase of story drift angel, damage of joint panel was inhibited by the fiber bridging effect comparing to specimen No.24. And also the maximum loads of beam-column joints increase by adding fiber. It can be recognized that part of the shear force was carried by PVA fibers. From the comparison between specimens No.32 and No.33, of which maximum load is $461 \mathrm{kN}$ and $468 \mathrm{kN}$ respectively. This indicates that casting direction of panel zone do not affect shear capacity of PVA FRCC beam-column joint significantly.

The cracks pattern of panel zone at each maximum load cycle are shown in Fig. 5. Shear cracks were observed on the surface of panel zone of both two specimens. As shown in Fig. 6, three penetrating cracks were occurred after the maximum load in the cover of specimen No.33 along the middle main reinforcing bars direction. Red dot lines indicate 
the positions of the main reinforcing bars along the longitudinal direction of column. The surface of No.33 facing to the camera is also the side surface during vertical casting. Due to the existing of main bars, it is considered that fibers rarely distribute in this plane which leads to the reduction of fibers. However, comparing to specimen No.32, the load of No.33 is a little higher because of the enough distribution of fiber in the core part of panel zone.

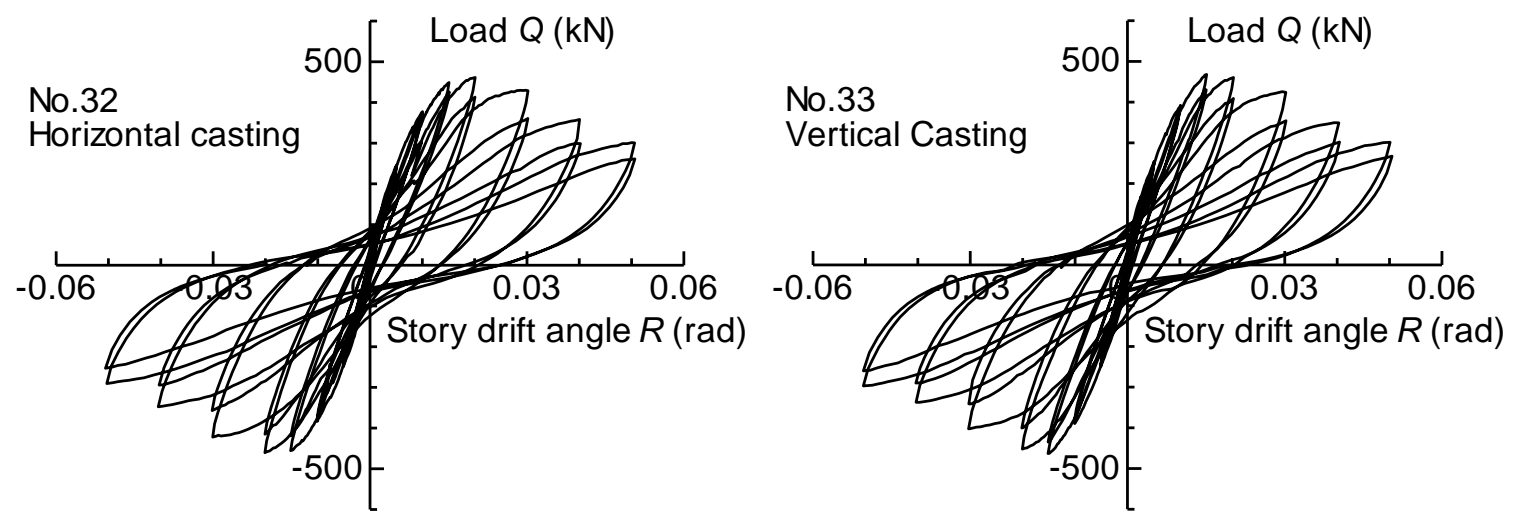

Figure 4. Load-story drift angle curve


Figure 5. Crack pattern at maximum load (No.32 at 1/50 rad, No.33 at 1/67 rad)

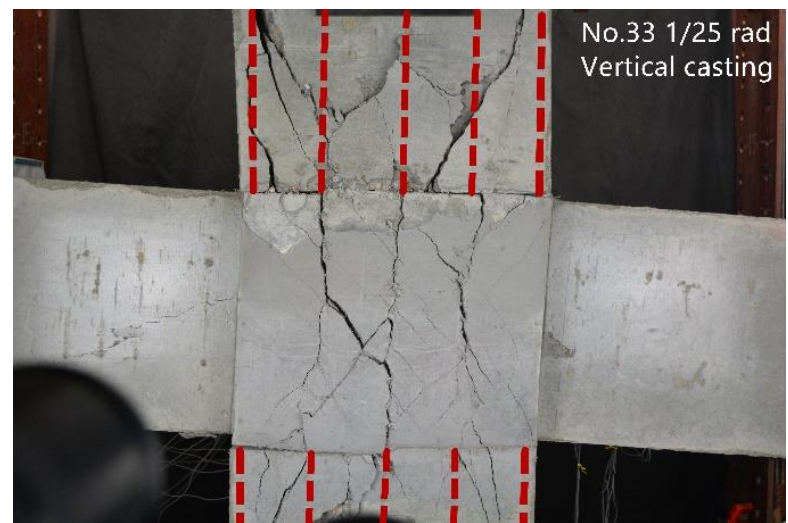

Figure 6. Position of main reinforcing bars in column 


\section{Comparison of skeleton curves}

Skeleton curves of specimens No.25 (horizontal casting only), No.32 (horizontal casting + vibrator) and No.33 (vertical casting + vibrator) are shown in Fig. 7. The maximum load of specimen No.25 is $443 \mathrm{kN}$ which is smaller than that of specimen No.32. This suggests that using a vibrator rod during casting affects the shear performance of PVA FRCC beamcolumn joint.

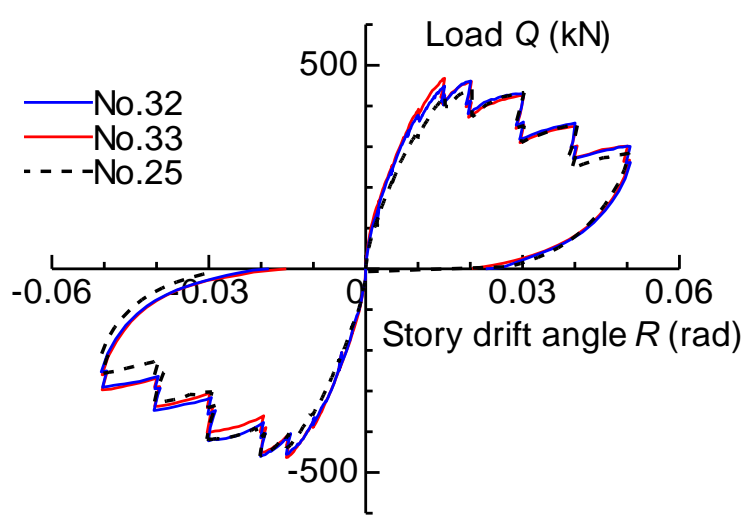

Figure 7. Comparison of skeleton curves

\section{CONCLUSION}

In this study, the loading test of PVA FRCC beam-column joint was conducted to evaluate the influence of fiber orientation on structural performance of beam-column joint using PVA FRCC in panel zone. The maximum load of all specimens are higher than specimens without fiber. According to the experimental results, specimens of horizontal casting and vertical casting show almost the same shear capacities. Using a vibrator rod during casting has an influence on shear capacity of PVA FRCC beam-column joint.

\section{REFERENCES}

Kanakubo, T., Miyaguchi, M., and Asano, K., (2016). "Influence of Fiber Orientation on Bridging Performance of Polyvinyl Alcohol Fiber-Reinforced Cementitious Composite." Materials Journal, American Concrete Institute, Vol.113, No.2, 131-141.

Laranjeira, F., Aguado, A., Molins, C., Grünewald, S., Walraven, J. and Cavalaro, S., "Framework to Predict the Orientation of Fibers in FRC: A Novel Philosophy," Cement and Concrete Research, V. 42, No. 6, 2012, pp. 752-768. doi: 10.1016/j.cemconres.2012.02.013.

Sano, N., Yamada H., Miyaguchi, M., Yasojima, A. and Kanakubo, T. (2015) "Structural Performance of BeamColumn Joint using DFRCC" The 11 th Canadian Conference on Earthquake Engineering-Facing Seismic Risk-, PaperID: 94163. 
Yamada, H., Ando, M., Yasojima, A., and Kanakubo, T., (2016) "Effect of Fiber Types on Shear Performance of Precast Concrete Beam-Column Joints using DFRCC" The $7^{\text {th }}$ International Conference of Asian Concrete Federation on Sustainable concrete for now and the future.

Watanabe, K., Ozu, Y., Miyaguchi, M., and Kanakubo, T., (2016) "Influence of Placing Method Considering Fiber Orientation to Bending Characteristics of DFRCC" The $7^{\text {th }}$ International Conference of Asian Concrete Federation on Sustainable concrete for now and the future. 